УДК 65.012.3 JEL M14

Долгая Ангелина Алексеевна

канд. экон. наук, ФГБОУ ВО

«Калининградский государственный

технический университет»,

г. Калининград

e-mail:dolgaya@dialoglan.ru

\section{Dolgaya Angelina}

Candidate of Economic Sciences,

Kaliningrad State Technical University,

Kaliningrad

e-mail:dolgaya@dialoglan.ru

\section{МОДЕЛЬ ВИРУСНЫХ ИЗМЕНЕНИЙ В ОРГАНИЗАЦИОННОЙ ТРАНСФОРМАЦИИ}

\begin{abstract}
Аннотация. Представлена модель вирусного управления организационными изменениями как результат междисииплинарных исследований, включающая структуру вируса, алгоритм и инструменты организачионного иммунитета, прерывающие процесс изменений. Вирус организационных изменений рассмотрен как цеенностная субстанция, проявляющаяся в отношениях, модели поведения, с оболочкой в форме информачионных сообщений. Алгоритм вирусных изменений состоит из трех этапов - внедрения, усвоения и умножения, объектом приложения в которых выступает лидер мнений в организации. В качестве иммунитета к изменениям на разных этапах трансформации выступают тип личности лидера мнений, уровень конформности сотрудников и сила организачионной культуры, рефлексия как инструмент контроля. Также в статье представлен ряд гипотез вирусной трансформации организации, требующих дальнейших исследований.
\end{abstract}

Ключевые слова: управление изменениями, организационная трансформация, лидер мнений, вирусное изменение, закон подражсания, изменение организационной культуры, вирус в управлении.

\section{VIRUS CHANGE MODEL IN ORGANIZATIONAL TRANSFORMATION}

\begin{abstract}
Virus technology organizational changes model is presented as an outcome of multidisciplinary research. The model consists of organizational virus structure, changes algorithm and immune instruments for process interruption. Author considers organizational transformation virus as a value substance, shown out in attitude, behavior pattern, with information message as an envelope. Virus organizational transformation algorithm consists of three phases - penetration, assimilation, multiplication, focused on the opinion leader. Immunity appears in different existences: opinion leader personality, level of conformity in organization and reflection as controlling and analytical tool. There are several hypothesis for further researches presented in the article.
\end{abstract}

Keywords: change management, organizational transformation, opinion leader, virus change, organizational culture change, virus in management.

Экспоненциальный рост объема вновь создаваемой информации и постоянные новации потребительского поведения ставят любую компанию сегодня перед необходимостью изменений. Однако организационные изменения обладают большой инерцией и часто не успевают за изменениями внешней среды. Распространение новых моделей работы по всей организации, принятие ее всеми вовлеченными сотрудниками требуют очень много вложений времени и усилий со стороны руководства. Корпоративные тренинги приобретают все большую популярность, в 2017 г. оборот обучающих услуг в США вырос на 32,5 \%, опередив по темпам роста большинство отраслей экономики [19]. Российские компании, несмотря на стагнацию в целом, также закладывают в бюджет значительные суммы на обучение и переобучение персонала [9]. Возрастающая частота изменений внешней среды требует и соответствующего сокращения периода внедрения изменений, роста скорости и снижения затрат на их осуществление.

Целью представленного в статье исследования явилась генерация идей и разработка новой модели управления изменениями в организации, характеризующейся высокой эффективностью - снижением периода изменений, затрат ресурсов на их осуществление при сохранении организационного масштаба трансформации.

Исследователи организационного поведения последнее десятилетие все шире используют понятие организации как живого организма. Начиная с метафор Г. Моргана, который организм ставил в один ряд с семью другими образами организации, Ф. Лалу об организации, как о живом организме говорит, как о необходимом условии успешного развития бизнеса в динамично изменяющейся, высоко волатильной среде [6; 7].

\footnotetext{
(С Долгая А.A., 2018 (c) (1)
} 
Организация, функционирующая как живой организм, также подвержена изменениям, эти изменения могут быть управляемыми и неуправляемыми. Качественные изменения в организации, как в любой динамической системе, инициируются бифуркационными воздействиями, незначительной сменой одного из ключевых параметров, приводящей через короткое время к серьезным сдвигам во всех характеристиках системы [1].

Известные сегодня и популярные инструменты управления изменениями в организации предполагают вовлечение большого количества сотрудников в программы на длительные периоды времени. Метод управления изменениями Д. Коттера, так называемая модель восьми шагов, предполагает формирование ряда групп из числа всех, причастных к изменяемому процессу, характеризуется высокими затратами времени и прочих ресурсов на его осуществление [15]. Широко известная модель ADKAR носит универсальный характер, также как и модель К. Левина, и применима к управлению изменением личности, но на уровне организации не развита до прикладной методологии. Другие инструменты управления изменениями нацелены главным образом на работу с возникающим сопротивлением при внедрении уже принятых руководством решений, то есть на избавление от проблем, вызванных изначально некомпетентным руководством [10].

Используя теоретические основы управления изменениями и теорий развития организации, мы сформулировали гипотезу о существовании инструмента управления высокоэффективными изменениями в организации, аналогичных вирусным изменениям, характеризующегося скоростью и низкими затратами ресурсов по сравнению с традиционными алгоритмами. Мы предположили, что вирусными изменениями также можно управлять, если создать алгоритм управления ими.

Настоящее исследование относится к категории междисциплинарных исследований, методы которых носят синтетический характер и скорее родственны общим методам познания. Вирус как объект исследований широко распространен не только в вирусологии, отрасли биологии, но и в прикладной математике, программировании, социальной инженерии, маркетинге и психологии $[14 ; 15 ; 17]$. Для применения эвристических подходов к исследованию новой темы вирусов в управлении изменениями нами в рамках магистерской программы Крауслаб была проведена серия фокусированных междисциплинарных семинаров [20]. В составе участников были представители всех перечисленных отраслей знаний, выступавшие с докладами в рамках своей профессиональной специализации. Генерация идей осуществлялась в форме мозговых штурмов, метаплана, ряда других интерактивных методов творческой деятельности.

Однако основным методом настоящего исследования явился метод аналогий, в частности, метод нестрогой структурной аналогии [2; 8]. Принимая за аналог поведение вируса в живых системах, мы выявили устойчивую последовательность событий, которую приняли за структуру поведения, алгоритм. В поведении биологического вируса, кроме трех этапов жизненного цикла, связанного с живой клеткой, мы также сфокусировались на явлении иммунитета как фактора влияния, структуре вируса организационных изменений и механизме его репликации в ядре клетки [15; 17]. Основные признаки поведения вируса в живой системе послужили прообразом для создания аналогии в алгоритме управления организационными изменениями (табл. 1). Для каждого признака было найдено соответствие в теории и практике менеджмента, социологии и маркетинге.

Таблииа 1

Аналогии в поведении вируса в биологии и в организационных изменениях

\begin{tabular}{|l|l|}
\hline \multicolumn{1}{|c|}{ Признаки поведения биологического вируса } & \multicolumn{1}{c|}{ Признаки вирусного изменения в организации } \\
\hline \multicolumn{2}{|c|}{ Этап «Внедрения» } \\
\hline Прикрепление & Выявление лидера мнений (ЛМ) \\
\hline Проникновение & Анализ ценностного профиля ЛМ \\
\hline \multicolumn{2}{|c|}{ Этап «Лишение оболочки» / «Усвоение» } \\
\hline Диссоциация оболочки & Размораживание \\
\hline Освобождение генома & Движение и замораживание \\
\hline & Этап «Репликация» / «Умножение» \\
\hline Синтез генома & Имитация поведения ЛМ \\
\hline Выход во внешнюю среду & Поддержка новой модели поведения \\
\hline
\end{tabular}


Окончание таблицы 1

\begin{tabular}{|l|l|}
\hline \multicolumn{1}{|c|}{ Признаки поведения биологического вируса } & \multicolumn{1}{c|}{ Признаки вирусного изменения в организации } \\
\hline \multicolumn{2}{|c|}{ Признаки общего характера } \\
\hline Структура вируса - геном и оболочка & $\begin{array}{l}\text { Структра вируса изменений - ценность как геном, инфор- } \\
\text { мационное сообщение как оболочка }\end{array}$ \\
\hline Иммунитет неспецифический & \begin{tabular}{l} 
Тип личности \\
\hline Иммунитет специфический
\end{tabular} \\
\hline
\end{tabular}

Составлено автором по материалам исследования

Признаки вирусного поведения, помимо алгоритма как последовательности событий, связанных с встречей с живой клеткой, включают еще и структуру самого вируса, как источника изменений, и феномена иммунитета, проявляющегося в разных формах [12; 17].

Исходным условием вирусного изменения является наличие самого вируса, который мы определяем, как ценностную компоненту, устойчивой комбинации подсознательного и сознательного: отношения, поведения и информационной оболочки. Ядром вируса организационных изменений выступает ценность, носимая личностью на подсознательном уровне как норма, определяющая отношение человека к любым событиям и явлениям [16]. Отношение, проявляющееся на эмоциональном уровне - результат сопоставления явления или события с нормой, безусловной ценностью, происходящего на подсознательном уровне восприятия (рис. 1). При отсутствии противоречий между ценностями отношение проявляет себя в поведенческой модели, видимой части вируса. Ценность, отношение и поведенческая модель - три структурных элемента, представляющих целостную неделимую сущность.

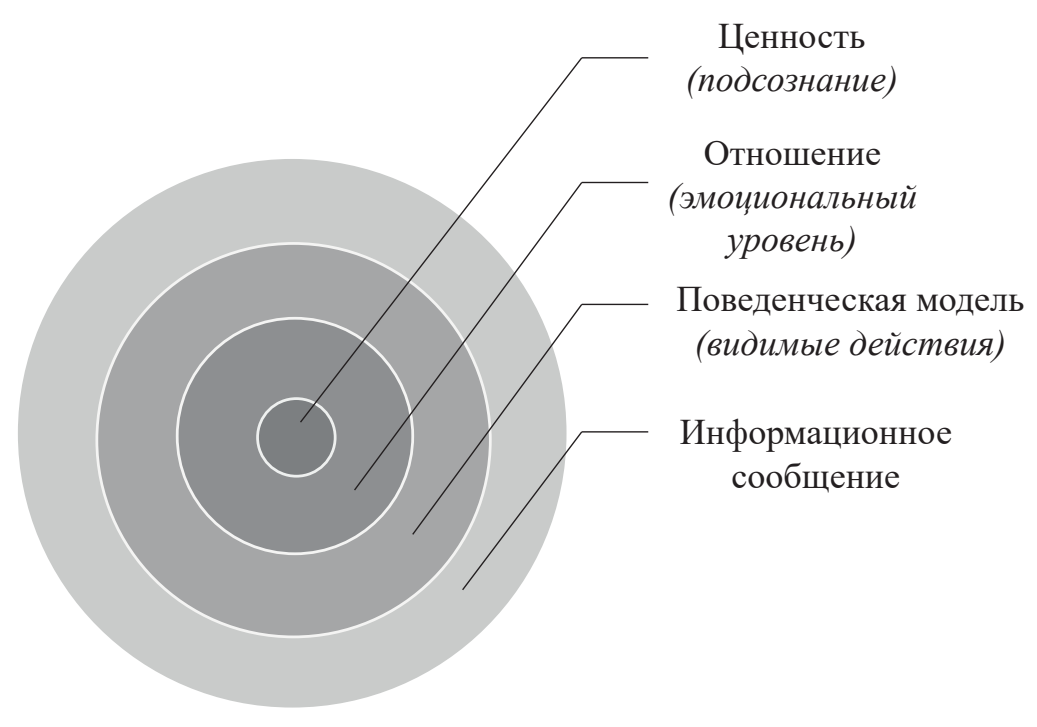

Составлено автором по материалам исследования

Рис. 1. Структура вируса организационного изменения

Последний слой - оболочка вируса, состоящая из информационного сообщения, несущего в себе смыслы, определяющие ценность, иерархию отношений на основе этой ценности и характеристики модели поведения на базе этой ценности. Оболочка вируса организационных изменений, по аналогии с биологическим вирусом, может отделяться от самого вируса при попадании его в организацию.

Модель управления вирусными изменениями, предложенная в результате исследований, состоит из алгоритма вирусных изменений и инструментов организационного иммунитета, препятствующих распространению изменений.

Распространение биологического вируса происходит в три укрупненных этапа: внедрение в клетку, лишение оболочки, если таковая у вируса имелась, и репликация [12]. 
Метод аналогий позволил нам определить три этапа вирусных изменений в организации как: внедрение, усвоение и умножение. Первый этап внедрения состоит из последовательных шагов по выявлению лидера мнений в организации, определению ценностного профиля в отношении к ценности, необходимой к внедрению, и создания картинки кризиса (рис. 2).

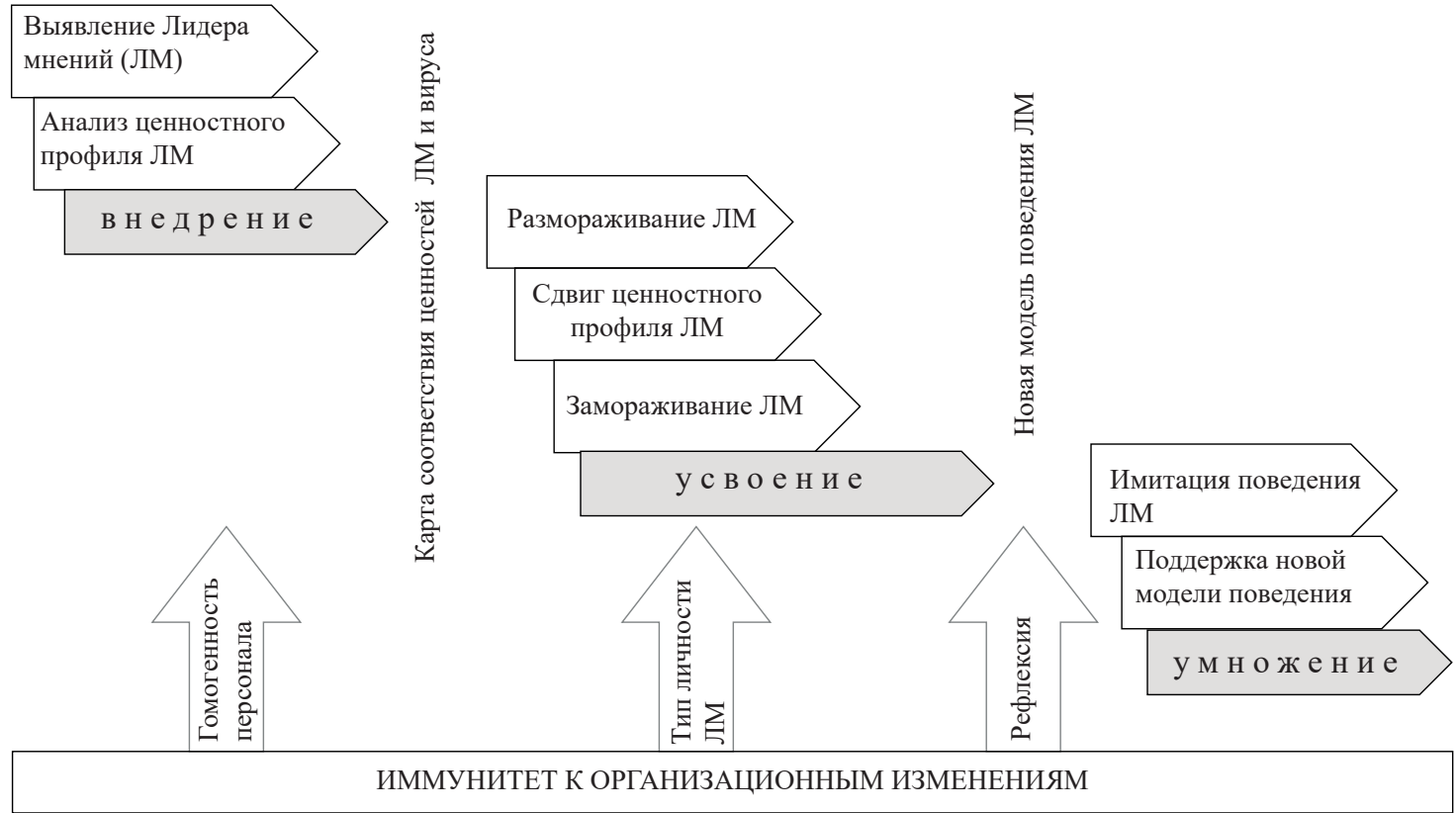

Составлено автором по материалам исследования

Рис. 2. Модель вирусного организационного изменения

Понятие лидер мнений (далее - ЛМ) было введено социологами П. Лазарсфельдом и Э. Катцем в отношении массовых коммуникаций и в дальнейшем широко использовалось в практике и теории политологии [18]. Сейчас феномен ЛМ исключительно популярен в маркетинге социальных сетей, в управлении организацией - его влияние и возможности применения не исследованы. Очевидно, что ЛМ - одна из форм лидерства в организации, формального или неформального, и может относиться к любому типу. Исходя из результатов социологических исследований, ЛМ характеризуется фокусированием на ценностях, профессионализмом и особенностью своих социальных связей [13]. Роль лидера мнений в организации не тождественна роли агента перемен, на которой основаны известные сегодня методы управления изменениями $[4 ; 5]$. Разница между этими ролями заключается в силе влияния на сотрудников организации, и поэтому фокусировка на ЛМ в алгоритме вирусного изменения имеет критическое значение для успеха.

Второй этап построен на модели изменений К. Левина в приложении к избранному лидеру мнений [14]. Целью этого этапа является изменение ценностной парадигмы ЛМ, исходя из существующих параметров организации, определенно неудовлетворительных в части вирусной компоненты, и в стремлении к целевым параметрам ценностного профиля. Трехступенчатая модель трансформации «замораживание-действие-размораживание» достаточно популярна и может применяться как в отношении индивидуума, так и к группам людей в организации. Вирусный характер эффекта проявляется достижением влияния на множество сотрудников через точечное воздействие на одного человека. Конечным результатом второго этапа может считаться не только принятая и усвоенная лидером мнений ценность, но и его новая модель поведения, подкрепленная соответствующими информационными сообщениями.

Третий этап по аналогии с поведением вируса и в соответствии с законом подражания, описанным Ж. Тардом, призван распространить желаемую модель поведения по всей организации [11]. Запуск этапа «Умножение» осуществляется без постороннего вмешательства, если предыдущие действия выполнены правильно: выбран действительный лидер мнений, новая ценность им усвоена и принята, как необходимая для организации, и обычное, рутинное поведение лидера мнений изменилось. Однако и на этом этапе трансформации существуют кри- 
тические факторы успеха (далее - КФУ), которые следует отслеживать при управлении процессом изменений. Основным КФУ, очевидно, является глубина целевых изменений по сравнению с существующим ценностным профилем культуры организации. Если предлагаемые ценностные инновации носят радикальный в восприятии большинства сотрудников характер, существует высокий риск отторжения новой модели поведения, даже воспринятой и тиражируемой ЛМ. В таком случае особенное значение приобретают действия по эмоциональной и операционной поддержке действий ЛМ в рамках трансформации. Такие действия могут включать весь набор управленческих инструментов от поддерживающей обратной связи до серии тренингов или бонусных программ.

Надо отметить, что нами предложен алгоритм управляемого вирусного изменения организации, поскольку первый этап предполагает осмысленный целевой поиск личности, имеющей значительное влияние на эмоциональное состояние сотрудников, оценку ценностного профиля этой личности в сравнении с ценностями трансформации. Последующие этапы также осуществляются неким субъектом управления в соответствии с поставленной целью изменений. Однако вирусная трансформация организации может быть и неуправляемой, спонтанной, связанной с изменениями в ценностных парадигмах лидеров мнений или появлением новых сотрудников в этой роли.

Модель вирусных трансформационных изменений не была бы полной без введения иммунитета как инструмента прерывания уже запущенного процесса. Как и в живой клетке, в организации иммунитет для каждой стадии трансформации носит специфический характер. На стадии внедрения препятствием может оказаться гомогенность персонала, отсутствие выраженного лидера мнений при высокой конформности и сплоченности коллектива [3]. На стадии усвоения в роли иммунитета выступит консерватизм ЛМ вообще, либо его особенное отношение к предлагаемым изменениям. И последний этап может быть прерван использованием рефлексии на всех уровнях организации, отражающей текущую ситуацию в сравнении с поставленными целями и желаемыми ценностями.

Метод аналогий позволил нам сформулировать гипотезы, требующие дальнейшего исследования. Первая гипотеза, ДНК организации - это ее ценностный профиль, определенный по шкале ценностных экстремумов. Он представляет собой интегральную взвешенную совокупность ценностей, принятых сотрудниками организации. Изменять культуру организации возможно только изменением ее ДНК - ценностного профиля.

Следующая гипотеза касается возможностей дальнейшего практического применения разработанной модели. Мы полагаем, что алгоритм вирусного изменения может быть использован как вектор, вводящий новый ген (ценность) в геном организации. Это означает, что предложенная в рамках настоящего исследования модель может служить универсальным инструментом для организационной трансформации: изменения культуры, внедрения инновационных подходов к функционированию организации, управленческой поддержки при смене стратегических ориентиров, при слиянии и поглощении компаний.

\section{Библиографический список}

1. Берже, П. Порядок в хаосе. О детерминистическом подходе к турбулентности / П. Берже, И. Помо, К. Видаль: Пер. с франц. - М.: Мир, 1991. - 368 с.

2. Бряник, Н. В. Общие проблемы философии науки: Словарь для аспирантов и соискателей / сост.и общ. Ред. Н. В. Бряник; отв. Ред. О. Н. Дьячкова. - Екатеринбург : Изд-во Урал. ун-та, 2007. - 318 с.

3. Долгая, А. А. Организационная культура и модель управления: исследование взаимосвязи. // Экономика и менеджмент систем управления. - № 3.1 (25). - 2017. - С. 117-124.

4. Долгая, А. А. Развитие вовлеченности персонала методами горизонтального управления // Вестник университета. 2017. - № 9. - С. 10-17.

5. Крылосова, М. В. Особенности социально-психологических компетенций руководителей первичного звена управления // Мир науки. - 2017. - Т. 5. - № 5. - С. 51.

6. Лалу, Ф. Открывая организации будущего. - М.: Манн, Иванов и Фербер, 2017. - 432 с.

7. Морган, Г. Образы организации. - М.: Манн, Иванов и Фербер, 2008. - 504 с.

8. Орехов, А. М. Методы экономических исследований: учеб. пособие. - М.: ИНФРА-М, 2009. - 392 с.

9. Пономарева, С. В. Рыночные тенденции развития компаний сферы интеллектуальных бизнес-услуг // Вестник университета. - 2017. - № 9. - С. 73-79.

10. Сычева, С. М. Роль менеджеров в проведении организационных изменений в корпорации // Вестник университета. 2014. - № 7. - C. 216-223. 
11. Тард, Ж.-Г. Законы подражания. - М.: Академический проект, 2011. - 304 с.

12. Belay, E. D. Desk encyclopedia of human and medical virology / E. D. Belay, L. B. Schonberger. - Boston : Academic Press, 2009. - P. 497-504.

13. Brown, S. Organizational opinion leader charisma, rolemodeling, and relationships / S. Brown, L. Chen, E. O’Donnell // International journal of organizational analysis. - 2017. - V. 25, I. 1. - pp. 80-102, https://doi.org/10.1108/ IJOA-10-2015-0924.

14. Kotter, J. P. Sense of urgency // Leadership excellence. - 2008. -V. 25. - p. 10.

15. Mahy, W. J., Van regenmortel M. H. V. (eds). Desk encyclopedia of general virology. - Oxford : Academic Press, 2009. - P. 24.

16. Oakley, D. A. Chasing the Rainbow: The Non-conscious Nature of Being / D. A. Oakley, P. W. Halligan // Frontiers in Psychology. - 2017. - V. 8. - P. 1924.

17. Patton J. T. Replication and transcription of the rotavirus genome / J. T. Patton, R. Vasquez-Del Carpio, E. Spencer. Curr. Pharm. 2004. Des. 10 (30): 3769-77. DOI:10.2174/1381612043382620. PMID 15579070.

18. Valente, T. Identifying Opinion Leaders to Promote Behavior Change // Health Education Behavior. - 2007. - 34 (6). - pp. 881-896.

19. 2017 Training industry report [Электронный ресурс] - Режим доступа: https://trainingmag.com/trgmag-article/2017-trainingindustry-report/ (дата обращения: 08.08.2018).

20. Innovation master program Krauslab [Электронный pecypc] - Режим доступа: http://new.krauslab.ru/ru/bd-ls/ (дата обращения: 08.08.2018).

\section{References}

1. Berzhe P., Pomo I., Vidal K. Poriadok v haose. O deterministskom podhode $\mathrm{k}$ turbulentnosti: per. s franz [About the determinist approach to turbulence]. M.: Mir, 1991. $368 \mathrm{p}$.

2. Brianik N. V. Obschie problem filosofii nauki: Slovar dlia aspirantov I soiskatelei [General issues of philosophy of science] / sos. I obsh. Red. N.V. Brianik; otv. Red. O.N. Diachkova. Ekaterinburg: Izd-vo Ural. Un-ta, 2007. 318 p.

3. Dolgaya A. A. Organizatsionnaya kultura I model upravlenia: issledovanie vzaimosviazi. [Organizational culture and management model: interrelation research], Ekonomika I menegement system upravlenia [Economics and management of management systems], 2017, I. 3.1 (25), pp. 117-124.

4. Dolgaya A. A. Razvitie vovlechennosti personala metodami horizontalnogo upravlenia [Employee engagement development on horizontal management model], Vestnik universiteta, 2017, I. 19, pp. 10-17.

5. Krylosova M. V. Osobennosti socialno-psyhologicheskih kompetencii rukovoditelei pervichnogo zvena uprevlenia [Socio-psychological specific of linear managers competencies], Mir nauki, 2017, vol. 5, I. 5, P. 51.

6. Lalu F. Otkryvaia organizatsii buduschego [Reinventing organizations]. M.: Mann, Ivanov I Ferber, 2017. 432 p.

7. Morgan G. Obrazy prganizatsii [Images of organization] / G. Morgan. M.: Mann, Ivanov I Ferber, 2008. 504 p.

8. Orehov A. M. Metody ekonomicheskih issledivanii: Ucheb. Posobie. [Economic research methods]. M.: INFRA-M, 2009. 392 p.

9. Ponomareva S. V. Rynochnie tendentsii razvitia kompanii sfery intellektualnih uslug [Market trends of intellectual services companies development], Vestnik Universiteta, 2017, I. 9, pp. 73-79.

10. Sycheva S. M. Rol menegerov v provedenii organizatsionnih izmenenii v korporatsii [Manager's role incorporative change implementation], Vestnik universiteta, 2014, I. 7, pp. 216-223.

11. Tard J.-G. Zakony podrajania. [Imitation laws]. M.: Akademicheskii proekt. 2011. 304 p.

12. Belay E. D., Schonberger L. B. Desk Encyclopedia of Human and Medical Virology. Boston : Academic Press, 2009, pp. 497-504.

13. Brown S., Chen L., O’Donnell E. Organizational opinion leader charisma, rolemodeling, and relationships, International Journal of Organizational Analysis, 2017, vol. 25, I. 1, pp. 80-102, https://doi.org/10.1108/IJOA-10-2015-0924/.

14. Kotter J. P. Sense of Urgency, Leadership Excellence, 2008, Vol. 25, p. 10.

15. Mahy W. J., Van Regenmortel M. H. V. (eds). Desk Encyclopedia of General Virology. Oxford : Academic Press, 2009. P. 24.

16. Oakley D. A, Halligan P. W. Chasing the Rainbow: The Non-conscious Nature of Being, Frontiers in Psychology, 2017, vol. 8:1924.

17. Patton J. T., Vasquez-Del Carpio R., Spencer E. Replication and transcription of the rotavirus genome. Curr. Pharm. 2004. Des. 10 (30): 3769-77. DOI:10.2174/1381612043382620. PMID 15579070.

18. Valente, T. Identifying Opinion Leaders to Promote Behavior Change, Health Education Behavior, 2007, 34(6), pp. 881-896.

19. 2017 Training industry report. Available at: https://trainingmag.com/trgmag-article/2017-training-industry-report/ (accessed 08.08.2018).

20. Innovation master program Krauslab. Available at: http://new.krauslab.ru/ru/bd-ls/ (accessed 08.08.2018). 